\title{
1 Characterisation of the R2R3 Myb subgroup 9 family of transcription factors in tomato
}

2 Gwen. V. Davis, Beverley. J. Glover.

3 Department of Plant Sciences, University of Cambridge, Downing Street, Cambridge CB2 3EA.

4 Author for correspondence: Beverley Glover.

$5 \quad$ Telephone: 441223333938

Email: bjg26@cam.ac.uk

7 Date of submission: $8^{\text {th }}$ January 2021

$8 \quad$ Number of tables and figures: 1 table 5 figures

$9 \quad$ Word count: 4998

10 Running title: Characterisation of R2R3 Myb subgroup 9 family in tomato

11 Acknowledgements:

12 We thank Matthew Dorling for excellent care of plants, Sam Brockington for help with

13 phylogenetic analysis, and members of the Glover lab for helpful discussions. GVD was

14 supported by the Natural Environment Research Council (grant number NE/L002507/1).

15 Author contribution and references:

16 BJG conceived of the idea and supervised the project. BJG and GVD designed the experiments

17 and developed the idea. GVD performed the experiments. GVD and BJG wrote the manuscript.

18 The manuscript was edited by GVD and BJG

19 Tables and supporting information: 3 supplementary figures, 1 supplementary table 


\section{Highlight:}

21 Characterisation of all members of an important family of transcription factors within 22 tomato showing that all are able to induce epidermal cell outgrowths to varying degrees.

Abstract:

Tomato (Solanum lycopersicum) has many epidermal cell outgrowths including conical cells and multiple types of trichomes. These include the anther-specific trichome mesh which holds the anthers connate. The R2R3 Myb Subgroup 9 family of transcription factors is involved in development of epidermal cell outgrowths throughout the angiosperms. No previous study has examined all members of this transcription factor family in a single species. All $7 R 2 R 3 M y b$ Subgroup 9 genes were isolated from tomato. They were ectopically expressed in tobacco to assess their ability to induce epidermal cell outgrowth. Endogenous expression patterns were examined by semi-quantitative RT-PCR at different stages of floral development relative to the development of anther trichomes. We report variation in the degree of epidermal cell outgrowth produced in transgenic tobacco for each ectopically expressed gene. Based on expression profile and ectopic activity, SIMIXTA-2 is likely involved in the production of leaf trichomes while SIMYB17-2 is the best candidate for the regulation of the anther trichome mesh. Analysis of the phenotypes of transgenic plants ectopically expressing all 7 genes has revealed the different extent to which members of the same transcription factor subfamily can induce cellular outgrowth.

Keywords: epidermal outgrowth, MIXTA, R2R3 Myb Subgroup 9 transcription factor, Solanum, tomato, trichome, transcription 


\section{Introduction:}

The R2R3 Myb proteins are a plant specific family of transcription factors which contain two copies of the Myb DNA binding domain (Meese et al, 1989) and carry out plant-specific functions (Martin and Paz-Ares, 1997; Kranz et al, 1998; Dubos et al, 2010.) The family can be divided into subgroups based on other conserved motifs usually external to the Myb domain (Stracke et al, 2001; Dubos et al, 2010). Some of these subgroups have been shown to regulate specific functions and phenotypes.

The R2R3 Myb Subgroup 9 subfamily of proteins is an ancient lineage (Brockington et al, 2013) that is especially important in the control of epidermal cell modification. Members of this protein family have the R2R3 Myb DNA binding domain composed of the R2 and R3 repeats (Jin and Martin, 1999) and also share their own subgroup 9 domain which forms a conserved motif around 30 peptides downstream from the second MYB repeat (Strake, Weber and Weisshaar, 2001). Duplication within this subgroup early in seed plant evolution led to the creation of two gene lineages: 9A and 9B (Brockington et al, 2013). These lineages underwent further duplication and sub functionalisation, leading to four clades of genes within the R2R3 subgroup 9 family in the eudicots (Brockington et al, 2013). These four subclades were named by Brockington et al (2013): subgroup 9A: MIXTA and MIXTA-like; and subgroup 9B: Myb17 and Myb17-like. Subgroup 9A and 9B proteins have been shown to perform a range of functions in the control of epidermal cell outgrowth, but the roles of the subgroup 9B proteins are less well understood than those of subgroup 9A (Brockington et al, 2013).

R2R3 Myb Subgroup 9 proteins are involved in the regulation of expression of genes involved in directional cell outgrowth: producing trichomes, conical cells and papillae. These epidermal cell outgrowths have been shown, in some cases, to follow the same developmental pathway, with differences in the timing of expression resulting in the different morphologies. For example, if cell division has finished when cell outgrowth occurs then expression can result in conical cells, however expression during cell division may result in the development of multicellular trichomes (Glover et al, 1998). A role for these genes in the regulation of epidermal cell outgrowth has been demonstrated in a variety of species and shown to be conserved throughout the angiosperms in Antirrhinum majus (Noda et al, 1994), Petunia hybrida (Baumann et al, 2007), Arabidopsis thaliana (Baumann et al, 2007), Thalictrum thalictroides (Di Stilio et al, 2009), cotton fibre initiation and development (Walford et al, 2011) and elongation (Machado et al, 2009), Mimulus guttatus (Scoville et al, 2011), Medicago truncatula (Gilding and Marks, 2010) and in Lotus japonicus (Brockington et al, 2013). R2R3 Myb subgroup 9 genes were first shown to be involved in epidermal cell outgrowth in Antirrhinum majus where the expression of the subgroup 9A gene MIXTA in the petal epidermis was found to be necessary for the formation of conical cells (Noda et al, 1994). It was further shown that the MIXTA gene was also sufficient for the production of conical cells when ectopically expressed in Antirrhinum and in heterologous hosts (Glover et al, 1998; Martin et al, 2002.) However, despite the wealth of studies examining individual members of this transcription factor family, no study has examined all members of the 
subgroup 9 family from a single species and so it has not been possible to date to draw conclusions about relative functions and phenotypic effects of the different members of the family.

Solanum lycopersicum (tomato) is an economically important crop plant. All species of the genus Solanum are buzz pollinated. Tomatoes produce multiple types of trichomes on all epidermal surfaces of the plant and there is considerable diversity in the density, morphology and chemical composition of trichomes (Schilmiller et al, 2008). Three main types of glandular trichomes have been described in Solanum lycopersicum, (type I, VI and VII) as well as two types of nonglandular trichomes (II and III), (Luckwill, 1943). An additional type of glandular trichome, type IV, is abundant in the wild tomato species S. pennellii, but is absent in cultivated S.lycopersicum, despite the close relationship between these species (Luckwill, 1943; Antonious, 2001). Each of the types of trichomes found in tomato are morphologically distinct. Of the glandular trichomes, type I have a multicellular base and long multicellular stalk (approximately $2 \mathrm{~mm}$ ) with a small glandular tip at the end. The type IV trichomes are shorter with a unicellular base. Type VI trichomes also have a shorter multicellular stalk (approximately $0.1 \mathrm{~mm}$ ) but with a four celled glandular tip. Type VII trichomes are even shorter (less than $0.05 \mathrm{~mm}$ ) with a unicellular stalk and a glandular tip consisting of between four and 8 cells (Luckwill, 1943). The non-glandular trichomes types found in tomato (I and III) are similar in length, at between 0.2 and $1 \mathrm{~mm}$. However they differ in that Type I have a multicellular base while type III have a uniceullar base (Luckwill, 1943). Trichomes are important in resistance to herbivore attack, by providing mechanical resistance that obstructs the movement of arthropod herbivores (Kennedy, 2003; Simmons et al, 2005), making the plant less palatable (Kariyat et al, 2017; Pollard and Briggs, 1984) and, in the case of glandular trichomes, producing secondary metabolites for toxicity or entrapment of herbivores (Uphof, 1962; Thurston, 1970; Levin, 1973, Wagner et al, 2004).

The trichomes of tomato play an additional, highly unusual, role. In tomato the anthers are held together in a connate structure by a mesh of interlocking trichomes (Glover et al, 2004). These trichomes are multicellular but short and non-glandular, they are also distinct morphologically from the other trichome types found elsewhere on tomato. This fused 'pepper pot' anther cone is generally uncommon in the genus Solanum but is found in all members of the Tomato subclade of Solanum (including all tomato wild-relatives such as S. pimpinellifolium and S. penellii). Solanum flowers are pollinated by pollen-gathering bees, which sonicate the flowers to release pollen from the pores at their tips, a process known as buzz pollination. The fused cone of anthers in tomato results in all the anthers being sonicated together as a single unit during buzz pollination. This is hypothesised to increase pollination efficiency and pollinator foraging efficiency (Glover et al, 2004).

Conical cells are another form of epidermal cell outgrowth found in tomato. Conical cells play an important role on the petals of many flowers (Kay et al, 1981; Martin and Glover, 2007; Whitney et al, 2009), where they provide improved grip to pollinating insects interacting with the flower (Whitney et al, 2009, Alcorn et al, 2012). Conical cells can be found on the petals of tomato, 
although they have been lost in some other species of the genus Solanum (Alcorn, 2013). The anther trichomes of tomato are unicellular and strongly resemble elongated conical cells, further supporting a developmental link between these specialised epidermal cell types.

Previous work has identified functions for some members of the Myb Subgroup 9 family of transcription factors in tomato prior to this study. The most studied of these genes is named in this study SIMIXTA-like (Solyc02g088190, a member of the MIXTA-like clade of Subgroup 9A) and was referred to as SlMixta-like by Lashbrooke et al (2015). These authors silenced SIMIXTAlike in tomato and found that the transcription factor promotes the development of conical cells in the epidermis of fruit and acts as a positive regulator of fruit cuticular lipid biosynthesis and assembly. The same gene was identified by Galdon-Armero et al (2000) who used introgression lines to identify genomic regions involved in epidermal cell outgrowth. The authors used ViGS, genome editing and overexpression studies to reveal a role for SIMIXTA-like as a negative regulator of leaf trichome development and a positive regulator of petal conical cell outgrowth. Ewas et al (2016) studied the gene named in this paper SIMIXTA-3 (Solyc01g010910, a member of the MIXTA clade of Subgroup 9A), which they referred to as SIMX1or SIMIXTAlike-1. This gene was shown to be involved in the modulation of drought resistance and also metabolic processes. Overexpression of SIMIXTA-3 in tomato resulted in increased drought tolerance and improved fruit quality, while silencing by RNAi (RNA interference) resulted in the opposite (Ewas et al, 2016). The transcription factor has also been implicated in trichome initiation (Ewas et al, 2016).

The diversity of epidermal cell outgrowths in tomato make it an ideal model in which to explore the function of the Myb subgroup 9 genes, with a particular focus on understanding the development of the unusual anther trichomes.

\section{Materials and Methods:}

\section{RNA extraction and cDNA synthesis}

Wild Type (WT) Solanum lycopersicum was the cultivar 'Moneymaker'. For isolation of R2R3 Myb subgroup 9 candidate genes, tissue was harvested from flowers, young leaves, buds of various floral growth stages, cotyledons, young roots, hypocotyls and apical meristems. These tissues were pooled. Tissue selection was guided by use of the Tomato efp Browser at Bar.UToronto.ca, Rose Lab Atlas (http://bar.utoronto.ca/efp_tomato/cgi-bin/efpWeb.cgi). Concert Plant ${ }^{\mathrm{TM}}$ RNA Reagent (Invitrogen) was used as per manufacturer's instructions. RNA was DNase treated and purified using phenol:chloroform purification. cDNA was synthesised using BioScript $^{\mathrm{TM}}$ (Bioline). RNA for semi-qRTPCR was extracted using a Trizol buffer method. The cDNA for semi-qRTPCR was synthesised using the Superscript II retrotranscription Kit (Invitrogen). 
157 Identification and isolation of all members of R2R3 MYB Subgroup 9 family of 158 transcription factors from Solanum lycopersicum

159 All members of the R2R3 MYB subgroup 9 family of transcription factors in Solanum

160 lycopersicum were identified through a BLAST search (NCBI) for the conserved motif of the

161 subgroup 9A and 9B transcription factor families. The subgroup membership was also confirmed

162 by phylogenetic analysis using the phylogeny of (Brockington et al, 2013) as a framework. This

163 phylogeny was a GARL1 maximum likelihood phylogram of 220 members of the subgroup 9

164 R2R3 Myb genes and the candidate genes were manually aligned with the phylogram at the level

165 of amino acids.

166 Gene specific primers were designed to amplify the full length coding sequence of each of the 167 candidate genes. Primers used can be found in Supplementary Information (supplementary table

168 ST1). Coding sequences were amplified using Phusion High Fidelity DNA Polymerase. Correct

169 amplification was confirmed by sequencing with gene specific primers and alignment using

170 Clustal Omega against the sequenced tomato genome as viewed on Phytozome V12.1 and Sol

171 Genomics Network (Current Tomato Genome Version SL3.0 and Annotation ITAG3.10).

\section{Tobacco transformation}

173 The coding sequence of each of the R2R3 subgroup 9 genes was cloned into a modified version 174 of pGreen (Hellens et al, 2000), containing two copies of the CaMV35s promoter and the 35S 175 terminator to drive constitutive expression in plant tissues.

176 Nicotiana tabacum 'Samsun' was transformed using a modification of the leaf disk method of 177 Horsch et al (1985).

\section{Genotyping of transgenic tobacco}

179 PCR with genomic DNA as template used gene specific primers or a gene specific forward primer with the 35S Reverse Primer (detailed in Supplementary Information). Once presence of the transgene was confirmed, expression was analysed. RNA was extracted using either a

182 CTAB-based protocol or Trizol buffer, and was cleaned using a phenol:choloroform purification before DNase treatment. PCR with RNA template was used to confirm the absence of gDNA before cDNA synthesis using the Superscript II retrotranscription Kit (Invitrogen). PCR to confirm expression of the transgene was conducted using gene specific primers, with ubiquitin primers as a positive control and WT tobacco gDNA as a negative control.

\section{Phenotyping of transgenic tobacco}

188 A minimum of five transgenic lines per construct, all shown to be expressing the transgene, were 189 analysed. 
Characterisation of transgenic line phenotypes was conducted using the Keyence light microscope VHX-5000 and the Zeiss EVO HD15 cryo-scanning Electron Microscope. For SEM tissue was mounted using a mix of colloidal graphite (G303, Agar Scientific.ltd. unit 7) and O.C.T compound (Scigen Tissue-Plus®, O.C.T. Scigen Scientific Gardena, LA90248USA). This glue was mixed in a ratio of $1 / 3$ colloidal graphite to $2 / 3$ O.C.T. The samples were cryogenically frozen and then underwent a sublimation of 5-9 minutes at $-90^{\circ} \mathrm{C}$. They were sputter coated with $5 \mathrm{~nm}$ of platinum.

\section{Gene expression analysis}

Floral stages for gene expression analysis were determined according to macroscopic features of organ position and trichome mesh development on the anthers, defined at each stage. Stages of tomato flower development were imaged using SEM of epoxy resin casts (Green and Linstead, 1990). Three pools of tissue were collected for each stage. Each pool contained multiple individuals, but approximately the same number of individuals were in each pool. For Stage 1 and Stage 2 the whole bud was collected. For later stages anthers were dissected separately. The reference gene used for the semi-qRTPCR was the tomato CAC gene (SGN-U314153, Clathrin adaptor complex Subunit), which has previously been shown to have consistent and stable expression levels in tomato floral tissue (Expósito-Rodriguez et al, 2008). The reference gene primers used were those described in (Expósito-Rodriguez et al, 2008). $M y b$ gene primers were tested for specificity against each of the 7 genes cloned into pBLUEscript. $5 \mu 1$ of the PCR reaction was removed after 30, 35 and 40 cycles and analysed on a $1.5 \%$ agarose gel.

\section{Results}

There are seven members of the $R 2 R 3 M Y B$ subgroup 9 family of transcription factors in Solanum lycopersicum

A BLAST search of the tomato genome for the diagnostic motif of the MYB subgroup 9 transcription factor family revealed the presence of 7 candidate genes in Solanum lycopersicum (figure 1A). The candidate genes were divided into the subclades $9 \mathrm{~A}$ and $9 \mathrm{~B}$ by the presence of a further diagnostic motif (figure 1Aa). Subgroup membership was also confirmed by phylogenetic analysis using the phylogeny of Brockington et al, 2013 as a framework. The positions of the 7 tomato genes are shown in figure $1 \mathrm{~B}$ and supplementary figure $\mathrm{S} 1$. Five of the genes fell into Subgroup 9A, with four of these belonging to the MIXTA subclade (SIMIXTA-1, SIMIXTA-2, SIMIXTA-3, SIMIXTA-4) and one belonging to the MIXTA-like subclade (SlMIXTA-like-1). Two of the genes belonged to the MYB17 subclade of subgroup 9B (SIMYB17-1, SIMYB17-2). No members of the subclade MYB17-like were found in the tomato genome.

All of the Subgroup 9A genes induced epidermal outgrowth when expressed ectopically in tobacco, but by different amounts 
Five independent lines were analysed for each construct, with transgene expression confirmed by RT-PCR (Supplementary figure S2; only 4 lines shown for SIMIXTA-like1). All of the transgenic plants had generally normal growth habits, with leaves and flowers of macroscopically wild type appearance. However, microscopic analysis revealed epidermal outgrowth on a number of organs. Each of the five Subgroup 9A genes induced outgrowth of epidermal cells when ectopically expressed in tobacco. Representative SEM images of a single transgenic line per construct are shown in figure 2, in comparison to wild type tissues (figure 2A-D).

Lines ectopically expressing SIMIXTA-1 had anthers which did not dehisce even when flowers matured. The transgenic plants had to be pollinated by hand. Examined using cryo-SEM the entire anther surface was covered in trichome-like epidermal cell outgrowths and conical cells (figure 2E). Some of these outgrowths were observed to be branched, and some had stomatal guard cells at the tip of the outgrowth. The epidermal surface of the ovary, usually composed of flat cells in the wild type, had many trichome-like outgrowths which were more elongated than those found on the anther surface and were in places multi-lobed (figure 2F). Ectopic conical cells were observed on the leaf epidermis, particularly on the adaxial side (figure 2G1 and figure 2H1). Ectopic branching trichomes were observed on both the adaxial and abaxial leaf epidermis (figure $2 \mathrm{G} 2$ and figure $2 \mathrm{H} 2$ ).

In contrast lines ectopically expressing SIMIXTA-2 had only a weak epidermal outgrowth phenotype. The epidermal surface of the anthers had occasional glandular trichomes(figure 2I1). Non-glandular trichome-like outgrowths were also observed along the anther connective (figure 2I2) and on the side of the anther to a lesser degree. Anthers were able to dehisce and overall were not dramatically different from WT. The epidermal surface of the ovary was smooth and resembled WT (figure 2J). The leaves had some branched trichomes on the adaxial side but otherwise resembled WT (figure $2 \mathrm{~K} 1$ and $2 \mathrm{~L} 1$ ).

Lines ectopically expressing SIMIXTA-3 also showed only a weak epidermal outgrowth phenotype and largely resembled WT. Glandular trichomes were present on the anther epidermal surface (figure 2M1) as well as some non-glandular trichomes on the anther connective, however the anthers dehisced normally (figure $2 \mathrm{M}$ ). The surface of the ovary contained some cells which had grown out from the plane of the tissue, but these conical cells were not very pronounced (figure 2N1). The leaves had branched trichomes, both glandular and non-glandular, on the adaxial surface (figure 2O1) but the abaxial side of the leaf resembled WT (figure 2P).

Lines ectopically expressing SIMIXTA-4 had a stronger phenotype, similar to those expressing SIMIXTA-1. The general shape of the anther epidermal cells was conical (figure 2Q1). Glandular trichomes (figure 2Q2), non-glandular trichomes (figure 2Q3) and stomata were also found on the anther epidermal surface (figure 2Q4). The conical shape of the epidermal cells of the anther became more pronounced as the anther reached maturity and began to dehisce. Glandular trichomes were also more exaggerated and numerous on the anther connective. The anthers were able to dehisce, to a limited extent. Trichomes were also observed on filaments of mature anthers 
but not on immature anthers. The ovary epidermal cell surface had conical cells (figure 2R1) towards the base of the ovary and some trichome like outgrowths were also observed (figure 2R2). Branched trichomes were occasionally observed on the leaf epidermal surface on both sides of the leaf (figure $2 \mathrm{~S}$ and $2 \mathrm{~T}$ ).

Lines ectopically expressing SIMIXTA-like had glandular trichomes (figure 2U1), non-glandular trichomes (figure 2U2) and stomata (figure 2U3) on the anther surface, and the rest of the anther was covered in ectopic conical cells (figure 2U4). The epidermis of the ovary had conical shaped cells (figure 2V1), however the phenotype was not as strong as seen with SIMIXTA-1 and SLMIXTA-4. Occasional conical cells were also seen on the inside of the corolla tube. Branched trichomes were observed on the abaxial leaf surface (figure 2X1).

In summary, ectopic expression of SIMIXTA-1 and SIMXTA-4 induced extensive epidermal cell outgrowth, SIMIXTA-like induced an intermediate phenotype, and SIMIXTA-2 and SIMIXTA-3 induced only weak epidermal outgrowth.

Both of the Subgroup 9B genes induced extensive epidermal outgrowth when expressed ectopically in tobacco

Five independent lines were analysed for each construct, with transgene expression confirmed by RT-PCR (Figure S3). All of the transgenic plants had generally normal growth habits, with leaves and flowers of macroscopically wild type appearance. Representative SEM images of a single transgenic line per construct are shown in figure 3 , in comparison to the same wild type tissues shown in figure 2 (figure 3A-E). Both of the Subgroup 9B genes induced extensive outgrowth of epidermal cells when ectopically expressed in tobacco, producing very strong phenotypes.

Lines ectopically expressing SIMYB 17-1 had a very strong anther phenotype. The anthers were unable to dehisce and the plants had to be hand pollinated. The anther epidermis was entirely converted to trichomes (figure 3F1) and conical cells (figure 3F2), most exaggerated at the anther connective (figure $3 \mathrm{~F}$ ). These outgrowths were also present on the filament. Some of the trichomes had stomata on the tip (figure 3F3). The epidermal surface of the ovary had trichomelike outgrowths with a mix of long and short trichomes (figure 3G1) and some of the outgrowths were multi-lobed (figure 3G2).). The adaxial side of the leaf had branching trichomes (figure $3 \mathrm{H} 1$ ) and some of the epidermal surface cells had conical outgrowths (figure $3 \mathrm{H} 2$ ). The abaxial surface of the leaves had large numbers of branched trichomes and many conical cells (figure 3I1). The normally flat inner corolla tube had conical cells and occasionally longer trichomes (Figure 3J1).

Lines ectopically expressing SIMYB17-2 also had anthers which were unable to dehisce, and had to be hand pollinated. The anthers were completely covered in epidermal cell outgrowths both in the form of trichomes and conical cells (figure 3K). Sometimes stomata were on the end of these trichomes (figure $3 \mathrm{~K} 1$ ). Longer glandular trichomes were also sometimes observed at the anther 
connective. The anther filaments also had trichomes on the surface. The epidermal surface of the ovary was entirely composed of cellular outgrowths which were most exaggerated at the base of the ovary (figure 3L). Branched trichomes were seen on the adaxial leaf surface (figure 3M1). Conical cells were seen on the abaxial surface on and around the leaf vein (figure $3 \mathrm{~N}$ ). Some conical cells (figure 301) were observed on the inside of the corolla tube along with some trichomes (figure 302).

The anther trichome mesh develops at an intermediate stage of bud development

To assess the timing of anther trichome development we divided tomato flower development into 7 stages, mainly determined by the relative position of the calyx and the corolla (figure 4A). Scanning electron microscopy revealed that the anther trichomes appear first as outgrowths in stage 2 (4B2 I), expanding in stage 3 and knitting the anthers together by late stage 3 (figure 4B3 II). Later in flower development additional cellular outgrowth is observed on the anther epidermis, with multilobed cells appearing at stage 4 (figure 4B 4III).

\section{Several of the Subgroup $9 M y b$ genes are expressed during early stages of tomato flower} development

The tomato eFP browser http://bar.utoronto.ca/efp_tomato/cgi-bin/efpWeb.cgi) gave an indication of which tissues the candidate genes were expressed in, and of the levels of expression. These data are summarised in table 1. Since a number of the genes appear to be expressed during flower development, we used semiquantitative RT-PCR to explore the timing of expression in floral tissues relative to the development of the anther trichome mesh (figure 5).

Expression was explored in whole floral bud at stage 1 (before anther trichomes emerge) and stage 2 (the earliest stage of anther trichome development), and in dissected anthers at stage 3 (when the trichome mesh is knitting together) and stage 4.

SIMIXTA-1 was expressed in the early stages of the bud development. Bands were visible in stage 1 and stage 2, most strongly in stage 1 with the expression fading as the bud developed: only a very faint band was visible in stage 4 at cycle 40. SIMIXTA-2 was not expressed in the floral tissues examined, or expressed at such a low level that it was not detectable, as predicted by the tomato eFP browser. SIMIXTA-3 was expressed only at a low level in all four of the floral stages. SIMIXTA-4 also had only very low level expression visible only after 40 cycles for each of the tissues. SIMIXTA-like-1 appeared to not be expressed in the floral stages examined, or only expressed at low levels. A band was visible only at cycle 40 and only very faintly in all tissues examined (a little stronger in bud stage 2). The SIMYB17-1 gene was expressed most strongly in the early stages of the development of the bud and during the stages in which the anther trichome mesh was developing. The gene was expressed in the floral tissue stages 1 and 2 (especially strongly compared to the reference gene in stage 2), after which expression level dropped. By stage 4 the band was very faint and only visible after 40 cycles. The SIMYB17-2 gene was expressed in all floral stages studied, but was expressed most strongly in early stages of bud 
development: the brightest bands were observed in stage 1 and especially 2 compared with the housekeeping gene. This was an almost identical expression pattern to that observed for SIMYB17-1.

Since stage 1 and 2 samples contained entire bud tissue, while stage 3 and 4 samples only contained anthers, any expression observed in stages 1 and 2 may not only arise from anther trichome development but might also reflect activity in the petals or sepals.

\section{Discussion}

The R2R3 Myb subgroup 9 family of transcription factors of Solanum lycopersicum were shown to various degrees to be capable of inducing outgrowth of cells when they were ectopically expressed in tobacco. This indicates that all these proteins have the potential to initiate epidermal cell outgrowths such as conical cells and trichomes within Solanum lycopersicum. However, the degree to which epidermal cell outgrowths were induced, and the number of tissues in which they were observed to act, varied from gene to gene.

The range of phenotypes exhibited in this study was similar to that reported in the set of studies in which the R2R3 subgroup 9A genes of Antirrhinum majus (A. majus) were ectopically expressed in tobacco (Glover et al, 1998; Perez-Rodriguez et al, 2005; Baumann et al, 2007; Jaffe et al, 2007). The strongest phenotype in those previous studies was observed in tobacco lines containing ectopically expressed AmMIXTA (Glover et al, 1998). In these lines trichomes were observed covering most tissues and with a particularly large amount of epidermal cell outgrowth observed on the ovary. These outgrowths included branched and glandular trichomes on the ovary and the production of conical cell protrusions on the epidermis on both sides of the leaf. None of the R2R3 subgroup 9 genes of Solanum lycopersicum produced phenotypes quite as extreme as this when ectopically expressed in tobacco. The strongest phenotypes were those seen in lines expressing the two subgroup 9B genes SlMyb17-1 and SlMyb17-2. These phenotypes were reminiscent of that of tobacco expressing AmMIXTA (a subgroup 9A gene). The majority of tissues exhibited epidermal cell outgrowths not found in the WT, with the ovary and the anthers particularly covered in trichomes of various types. However, no branched trichomes were found on the surface of the ovary, although the trichomes also sometimes had stomata on the end. Our sqRT-PCR analysed revealed that these two genes had nearly identical expression patterns in the tomato flower, with particularly strong expression at early stages of development, when the trichome mesh is beginning to form. This contradicts the eFP browser, which predicted that SlMyb17-1 would not be expressed in the flower but that SlMyb17-2 would.

The outgrowths on the ovary of the transgenic lines expressing SlMyb17-1 resembled the 'glovelike' papillae found on the surface of the tomato anther (figure 4B). Meanwhile, the outgrowths on the anther of these lines were very like the trichomes which make up the trichome mesh of WT tomato anthers. In combination with its expression profile in developing flowers (and persisting in later stages of anther development) this gene is a good candidate for the control of 
the development of the trichome mesh and/or 'glove-like' papillae on the anther surface. The transgenic lines expressing SlMyb17-2 also developed trichomes on the anthers and ovary that resembled those of the trichome mesh. The two $S l M y b-17$ genes could be considered likely candidates for the control of the development of the trichome mesh. They were both expressed most strongly in tissue stages 1 and 2, where the trichome mesh is developing. It is possible that the two genes function together or are redundant with one another. Previously studied members of the MYB17 clade of genes in subgroup 9B have not shown an involvement in epidermal cell outgrowth. AtMYB17 (Pastore et al, 2011) has been shown to be involved in flowering commitment, but no epidermal phenotype was seen in a mutant line. The gene was also shown to be involved in the regulation of activity of APETALA1 in the flowers of Arabidopsis thaliana and is thought to act together with LEAFY (Zhang et al, 2009). However it has been previously argued that with so much paralogy in the $M Y B$ subgroup 9 lineages it is possible that the AtMYB17 gene of Arabidopsis thaliana may have acquired a different role to other MYB17 representatives and that a possible role of $M Y B 17$ genes in the regulation of epidermal cell outgrowths should not be dismissed entirely (Brockington et al, 2013). Brockington et al (2013) also implicated the MYB17 lineage genes in epidermal outgrowth regulation because the Nicotiana EST-derived fragments nested within the MYB17 clade in their phylogenetic analysis were derived from trichome-specific transcriptomes.

A MYB17-like gene (LjMYB17-like) from Lotus japonicus was analysed by Brockington et al (2013) and, when ectopically expressed in tobacco, produced a very strong phenotypic effect. The epidermal cells on the adaxial and abaxial leaf surfaces became conical in shape and there was a reduced number of stomata. The filament of the stamen also gained trichomes and conical cells on its epidermal surface. The ovary surface was covered in long conical cells and the cells on the petal lobes had become elongated and glandular trichomes were also found (Brockington et al, 2013). No member of the MYB17-like clade was present in the tomato genome, but this previous study supports a role for subgroup $9 B$ genes more generally in epidermal cell outgrowth.

The A. majus subgroup 9 gene with the second strongest phenotype when expressed in tobacco was AmMYBML-1, another gene in the MIXTA clade (Perez-Rodriguez et al, 2005). The anthers of these lines were covered in conical cells and failed to dehisce as a result. The ovary surface was covered in a mixture of conical cells and trichomes. However the epidermal surface of the leaves was considered to be WT in appearance. The phenotype of lines expressing SIMIXTA-1 was reminiscent of this and could be considered the third strongest phenotype observed in this study. A mixture of conical cells and trichomes were observed on the ovary surface and trichomes were also found on the anther surface and consequently the anthers did not dehisce. Branched trichomes were also observed on the leaf surface and occasional conical protrusions on the leaf surface, however in general the phenotype was weaker than that observed in AmMIXTA lines and closer in resemblance to those of $A m M Y B M L-1$. 
The SIMIXTA-4 lines were also reminiscent in phenotype of the AmMYBML-1 study. However the phenotype was less strong than observed in SIMIXTA-1 lines. The ovary still exhibited both conical cells and trichomes, but the proportion of conical cells relative to trichomes was increased. The number of trichome outgrowths observed on the anther surface was less than that observed in SIMIXTA-1 lines and the anthers were able to dehisce as a result of only slightly conical shaped cells and some glandular trichomes rather than large numbers of simple trichomelike outgrowths. The leaves resembled WT tobacco.

Both the SIMIXTA-1 and the SIMIXTA-4 genes were expressed in developing flowers, but SIMIXTA-1 was expressed slightly more strongly in the early stages of development, while SIMIXTA-4 was expressed more strongly in later stages. This temporal separation of expression patterns could indicate differential roles in flower development, with SIMIXTA-4 potentially involved in later stage developmental processes such as the development of the glove-like papillae on the anthers.

The weakest phenotypes observed in this were those produced by ectopically expressing SIMIXTA-2 and SIMIXTA-3, which resulted in an even weaker phenotype than the weakest of the phenotypes obtained from expression of A. majus genes. Lines expressing SIMIXTA-2 and SlMIXTA-3 had a few branched trichomes on the leaf epidermis, and a few shallow conical cells on the ovary surface, similar to those found when expressing AmMYBML3 (Jaffe et al, 2007). The lack of expression of SIMIXTA-2 and Sl-MIXTA-3 in floral tissues suggests that these genes do not play a role in anther trichome mesh regulation. In a previous study of SIMIXTA-3 (SIMX1)it was shown that when over-expressed in tomato there was increased resistance to drought (Ewas et al, 2016). SEM images in that study showed increased numbers of trichomes on the leaves and stems of tomato lines overexpressing SIMIXTA-3 as well as increased leaf thickness. RNAi lines with downregulation of SIMIXTA-3 expression showed the opposite (Ewas et al, 2016).

The A.majus genes belonging to the MIXTA-like clade of Brockington et al (2013) (AmMYBML2 and $A m M Y B M L 3$ ) had the weakest phenotypes when expressed in tobacco (Baumann et al, 2007; Jaffe et al, 2007). The MIXTA-like genes from Arabidopsis thaliana (AtMYB16) and Petunia hybrida (PhMYB1) produced near identical phenotypes to that produced by ectopic expression of AmMYBML2 (Baumann et al, 2007), with some conical cells on the ovary epidermis and an extension of the petal conical cells. The TtMYBML2 gene of Thalictrum thalictroides also induces conical cells on the ovary and carpel and elongates those of the petal lobe (Di Stilio et al, 2009). The lines expressing SIMIXTA-like-1 in this study were reminiscent of this phenotype, yet slightly stronger. The ovary surface exhibited only conical cells and no trichomes, like the AmMYBML2 and AmMYBML3 phenotypes, yet conical cell-like protrusions were also observed on the anther surface (although they did not affect dehiscence). The conical cells on the petal lobe, where conical cells are observed in WT tobacco, also appeared longer in the SIMIXTA-like 1 expressing lines. The SIMIXTA-like 1 gene was found not to be expressed in flowers, suggesting no role in anther trichome development. SIMIXTA-like-1 has been previously studied and shown to be expressed significantly during tomato fruit development in both skin and flesh 
452 tissues (Lashbrooke et al, 2015, where it was referred to as SlMixta-like). It was also shown that 453 RNAi lines in which the gene was silenced in tomato resulted in the flattening of epidermal cells 454 and thinning of the cuticle in tomato fruit (Lashbrooke et al, 2015), so it is possible that the gene 455 is involved in epidermal cell outgrowths in other surfaces in addition to fruit cuticle. SIMIXTA-

456 like-1 has since been shown using CRISPR Cas9 knockout to be a negative regulator of trichome 457 development in leaves (Galdon-Armero et al, 2020) but to be a positive regulator of conical cell 458 outgrowths in petals and fruit, therefore serving different outgrowth regulatory purposes in 459 different tissues (Galdon-Armero et al, 2020).

460 Transgenic experiments using a heterologous host must always be interpreted with caution. In 461 this study we have not demonstrated that a particular gene performs a particular function, 462 because we have not worked in the endogenous host. However, by expressing the 7 members of 463 this subfamily from the same promoter in tobacco under the same conditions we can draw 464 conclusions about the relative ability of each protein to induce cellular outgrowth. This study 465 presents the first analysis of the complete set of MYB subgroup 9 transcription factors in a single 466 species. 
468 Supplementary Figures:

$469 \quad$ Figure S1: Phylogenetic analysis of R2R3 MYB subgroup 9 genes (with the position of

470 tomato genes included).

471 Figure S2: Analysis of expression of subgroup 9A genes in transgenic tobacco lines.

$472 \quad$ Figure S3: Analysis of expression of subgroup 9B genes in transgenic tobacco lines.

473 ST1: Table of primers used.

474

475 Acknowledgements

476 We thank Matthew Dorling for excellent care of plants, Sam Brockington for help with

477 phylogenetic analysis, and members of the Glover lab for helpful discussions. GVD was

478 supported by the Natural Environment Research Council (grant number NE/L002507/1).

479

480 Author contributions :

481 BJG conceived of the idea and supervised the project. BJG and GVD designed the experiments

482 and developed the idea. GVD performed the experiments. GVD and BJG wrote the manuscript.

483 The manuscript was edited by GVD and BJG

484

485

Data availability statement:

486 The data supporting the findings of this study are available from the corresponding author,

487 (Beverley Glover), upon request. 


\section{References:}

Alcorn K, Whitney H, Glover B. 2012. Flower movement increases pollinator preference for flowers with better grip. Functional. Ecology. 26,4,941-947.

Alcorn K. 2013. Pollinator behaviour and the evolutionary genetics of petal surface texture in the Solanaceae. PhD Thesis, University of Cambridge.

Antonious GF .2001. Production and quantification of methyl ketones in wild tomato accessions. Journal of Environmental Science and Health Part B. 36,835-848.

Baumann K, Perez-Rodriguez M, Bradley D et al. 2007. Control of cell and petal morphogenesis by R2R3 MYB transcription factors. Development, 134 ,9, 1691-1701.

Brockington SF, Alvarez-Fernandez R, Landis JB et al. 2013. Evolutionary Analysis of the MIXTA Gene Family Highlights Potential Targets for the Study of Cellular Differentiation.Molecular Biology and Evolution, 30,3, 526-540.

Dubos C, Stracke R, Grotewold, R et al. 2010. MYB transcription factors in Arabidopsis.Trends in Plant Science ,. 15, 10, 573-581.

Ewas M, Gao Y, Wang S, Liu X, Zhang H, Nishawy EME, Ali F, Shahzad R, Ziaf K, Subthain H, Martin C, Luo J.2016. Manipulation of SIMX1 for enhanced carotenoids accumulation and drought resistance in tomato. Science Bulletin.. 61,18,, pp.1413-1418.

Exposito-Rodriguez M, Borges AA, Borges-Perez A and Perez JA.2008. Selection of internal control genes for quantitative real-time RT-PCR studies during tomato development process. BMC Plant Biology, 8, 131.

Galdon-Armero J, Arce-Rodriguez L, Downie M Li J, Martin C.2020. A Scanning Electron Micrograph-based Resource for Identification of Loci Involved in Epidermal Development in Tomato: Elucidation of a New Function for the Mixta-like Transcription Factor in Leaves. Plant Cell Advance Publication. 10.1105/tpc.20.00127.

Glover BJ, Perez-Rodriguez M, Martin C.1998. Development of several epidermal cell types can be specified by the same MYB-related plant transcription factor. Development, 1253497 3508 .

Glover BJ, Bunnewell S, Martin C. 2004. Convergent evolution within the genus Solanum: The specialised anther cone develops through alternative pathways. Gene, 331,1-2, 1-7. 
Hellens RP, Edwards EA, Leyland NR et al. 2000. pGreen: a versatile and flexible binary Ti vector for Agrobacterium-mediated plant transformation. Plant Molecular Biology, 42,6,819832.

Jin H, Martin C. 1999. Multifunctionality and diversity within the plant MYB-gene family. Plant Molecular Biology, 577-585.

Kariyat RR, Smith JD, Stephenson AG et al. 2017. Non-glandular trichomes of Solanum carolinense deter feeding by Manduca sexta caterpillars and cause damage to the gut peritrophic matrix. Proceedings of The Royal Society B Biological Sciences, 284,1849.

Kay Q, O N, Daoud HS, and StirtonC. H.1981. Pigment distribution, light reflection and cell structure in petals.Botanical Journal of the Linnean Society ,. 83, 57-84.

Kennedy GG.2003. Tomato, pests, parasitoids, and predators: Tritrophic interactions involving the genus Lycopersicon. Annual Review of Entomology, 48: 51-72.

Kranz HD, Denekamp M, Greco R et al. 1998. Towards functional characterisation of the members of the R2R3-MYB gene family from Arabidopsis thaliana. The Plant Journal, 16May, 263-276.

Lashbrooke JG, Adato A, Lotan O, Alkan N, Tsimbalist T,Rechav K, Fernandez-Moreno JP, Widemann E, Grausem B, Pinot F, Granell A, Costa F, Aharoni A.2015. The Tomato MIXTA-like Transcription Factor Coordinates Fruit Epidermis Conical Cell Development and Cuticular Lipid Biosynthesis and Assembly. Plant Physiology, 169(December), p.pp.01145.2015. Available at: http://www.plantphysiol.org/lookup/doi/10.1104/pp.15.01145.

Levin DA. 1973. The Role of Trichomes in Plant Defence. The Quarterly Review of Biology . 48,1, Part 1, 3-15.

Luckwill LC .1943. The genus Lycopersicon: a historical, biological and taxonomic survey of the wild and cultivated tomato. Aberdeen University Studies, 120: 1- 44.

Machado A, Wu Y, Yang Youming et al. 2009. The MYB transcription factor GhMYB25 regulates early fibre and trichome development. Plant Journal, 59 52-62.

Martin C, Bhatt K, Baumann K et al. 2002. The mechanics of cell fate determination in petals. Philosophical Transactions of the Royal Society B, (May) 809-813.

Martin C, Paz-Ares J.1997. MYB transcription factors in plants. Trends in genetics. 13. (2). 6773.

Martin C, Glover BJ. 2007. Functional aspects of cell patterning in aerial epidermis. Current Opinion in Plant Biology, 10 70-82. 
Meese E, Meltzer PS, Witkowski CM, Trent JM. 1989. Molecular mapping of the oncogene MYB and rearrangements in malignant melanoma. Genes Chromosomes Cancer. 1989 Sep;1(1):88-94.

Noda K, Glover BJ, Linstead P et al. 1994. Flower colour intensity depends on specialized cell shape controlled by aMyb-related transcription factor. Nature 369 (6482) 661-664.

Pastore JJ, Limpuangthip A, Yamaguchi N et al. 2011 LATE MERISTEM IDENTITY2 acts together with LEAFY to activate APETALA1. Development, 138, 15, 3189-3198.

Perez-Rodriguez M, Jaffe FW, Butelli Eugenio et al. 2005, Development of three different cell types is associated with the activity of aspecific MYB transcription factor in the ventral petal of Antirrhinum majus flowers. Development, 132 ,2, 359-370.

Pollard AH, Briggs D. 1984. Genecological studies of Urtica dioica.L. III. Stinging hairs and plant-herbivore interactions. New Phytologist, 97, 507-522.

Schilmiller AL, Last R.L, Pichersky E. 2008. Harnessing plant trichome biochemistry for the production of useful compounds. The Plant Journal, 54, 4, 702-711.

Simmons AT, Gurr GM .2005. Trichomes of Lycopersicon species and their hybrids: effects on pests and natural enemies. Agricultural and Forest Entomology, 7: 265-276.

Stracke R, Werber M, Weisshaar B. 2001. The R2R3-MYB gene family in Arabidopsis thaliana. Current Opinion in Plant Biology, 4 ,5, 447-56.

Tattersall A, Glover BJ, Jaffe FW. 2007. Atruncated MYB transcription factor from Antirrhinum majus regulates epidermal cell outgrowth. Journal of Experimental Botany, 58 $, 6,1515-1524$.

Thurston R. 1970. Toxicity of Trichome Exudates of Nicotiana and Petunia Species to Tobacco Hornworm Larvae. Journal of Economic Entomology, 63 ,11, 272-274.

Uphof JCT. 1962. Plant hairs. Handb. der Pflanz. Anat. 4.

Wagner GJ, Wang E, Shepherd RW. 2004. New approaches for studying and exploiting an old protuberance, the plant trichome. Ann. Bot. 93 ,1, 3-11.

Walford S, Wu Y, Llewellyn DJ et al. 2011. GhMYB25-like : a key factor in early cotton fibre development. The Plant Journal, 65, 785-797.

Whitney HM, Chittka L, Bruce TJA et al. 2009. Report Conical Epidermal Cells Allow Bees to Grip Flowers and Increase Foraging Efficiency. Current Biology, 19 , 11, 948-953. 
Zhang Y, Cao G, Qu L, Gu H. 2009. Characterization of Arabidopsis MYB transcription factor gene AtMYB17 and its possible regulation by LEAFY and AGL15. Journal of Genetics and Genomics. 36,2, 99-107.

Tables

Table 1: A table summarising the expression of the $R 2 R 3 M Y B$ subgroup 9 candidate genes in Solanum lycopersicum.

This table summarises expression levels predicted by the eFP browser for the candidate genes.

\section{Figures}

Figure 1A: Cartoon of the proteins of the R2R3 MYB subgroup 9 genes of Solanum lycopersicum, with key motifs labelled.

Sol genomics codes are displayed beneath name the transcription factor is referred to within this paper. Lengths displayed are total amino acids.

\section{Figure 1B: Cartoon phylogeny of the R2R3 MYB Subgroup 9 family of transcription factors.}

Based on reconstruction by Brockington et al 2013. Placement of R2R3 subgroup 9 transcription factors within tomato is indicated.

Figure 2: SEM images of key tissues of transgenic tobacco ectopically expressing the Solanum lycopersicum subgroup $9 A$ genes.

The images shown are representative individuals of each line, from which a minimum of 5 individuals were examined per line. Wild-type tobacco tissues are shown as comparison. The tissues shown are anther surface and ovary surface as these tissues showed the most distinctive transgenic phenotypes and showed the most variation with expression of the different genes. A: WT tobacco anther, B: WT ovary epidermal surface. C: WT adaxial leaf surface. D: WT abaxial leaf surface. E: Anther surface of tobacco ectopically expressing SIMIXTA-1. F: Ovary surface of tobacco ectopically expressing SIMIXTA-1. G: Adaxial leaf surface of tobacco ectopically expressing SIMIXTA-1, G1 labels ectopic conical cells, G2 labels ectopic branched trichome. H: Abaxial leaf surface of tobacco ectopically expressing SIMIXTA-1, H1 labels ectopic conical cells, H2 labels ectopic branched trichome. I: Anther surface of tobacco ectopically expressing SIMIXTA-2, I1 labels ectopic glandular trichome, I2 labels ectopic non-glandular trichome. J: Ovary surface of tobacco ectopically expressing SIMIXTA-2. K: Adaxial leaf surface of tobacco ectopically expressing SIMIXTA-2, K1 labels ectopic branched trichome. L: Abaxial leaf surface of tobacco ectopically expressing SIMIXTA-2, L1 labels ectopic branched trichome. M: Anther surface of tobacco ectopically expressing SIMIXTA-3, M1 labels ectopic glandular trichome. N: 
Ovary surface of tobacco ectopically expressing SIMIXTA-3, N1 labels ectopic conical cells. O: Adaxial leaf surface of tobacco ectopically expressing SIMIXTA-3, O1 labels ectopic branched trichome. P: Abaxial leaf surface of tobacco ectopically expressing SIMIXTA-3. Q: Anther surface of tobacco ectopically expressing SIMIXTA-4, Q1 labels ectopic conical cells, Q2 labels ectopic guard cells, Q3 labels ectopic non-glandular trichome, Q4 labels ectopic glandular trichome. R: Ovary surface of tobacco ectopically expressing SIMIXTA-4, R1 labels ectopic conical cells, R2 labels ectopic non-glandular trichome. S: Adaxial leaf surface of tobacco ectopically expressing SIMIXTA-4. T: Abaxial leaf surface of tobacco ectopically expressing SIMIXTA-4. U Anther surface of tobacco ectopically expressing SIMIXTA-like-1, U1 labels ectopic glandular trichome, U2 labels ectopic non-glandular trichome, U3 labels ectopic guard cell, U4 labels ectopic conical cell. V: Ovary surface of tobacco ectopically expressing SIMIXTA-like-1, V1 labels ectopic conical cell. W: Adaxial leaf surface of tobacco ectopically expressing SIMIXTA-like-1. X:Abaxial leaf surface of tobacco ectopically expressing SIMIXTAlike-1, X1 labels ectopic branched trichome.

\section{Figure 3: The transgenic phenotypes of lines of tobacco ectopically expressing each of the R2R3 MYB subgroup $9 B$ genes of tomato.}

The images shown are representative individuals of each line, from which a minimum of 5 individuals were examined per line. Wild-type tobacco tissues are shown as comparison. The tissues shown are anther surface and ovary surface as these tissues showed the most distinctive transgenic phenotypes and showed the most variation with expression of the different genes. A: WT tobacco anther. B: WT ovary epidermal surface. C: WT adaxial leaf surface. D: WT abaxial leaf surface. E: WT corolla surface. F: Anther surface of tobacco ectopically expressing SlMYB17-1, F1 labels ectopic trichomes, F2 labels ectopic conical cells. G: Ovary surface of tobacco ectopically expressing SIMYB17-1, G1 labels ectopic trichome like outgrowths, G2 labels multilobed outgrowths. H: Adaxial leaf surface of tobacco ectopically expressing SIMYB17-1, H1 labels ectopic branched trichome, H2 labels ectopic conical cells. I: Abaxial leaf surface of tobacco ectopically expressing SIMYB17-1, I1 labels ectopic conical cells. J: Corolla surface of tobacco expressing SIMYB17-1, J1 labels ectopic conical cells. K: Anther surface of tobacco ectopically expressing SIMYB17-2, K1 labels ectopic guard cells on top of cell outgrowths. L: Ovary surface of tobacco ectopically expressing SIMYB17-2. M: Adaxial leaf surface of tobacco expressing SIMYB17-2, M1 labels ectopic branched trichome. N: Abaxial leaf surface of tobacco expressing SIMYB17-2. O: Corolla surface of tobacco expressing SIMYB17-2, O1 labels ectopic conical cells, O2 labels ectopic trichome.

\section{Figure 4: The stages of floral development and the anther epidermal cell outgrowths of Solanum lycopersicum.}

A. Six stages of tomato flower development chosen to reflect the development of the epidermal cell outgrowths on tomato anthers. B. SEM images of anther surface at stages 1 to 4 . Epidermal cell outgrowths begin to develop at stage 2 (I). By stage 3 the anther trichome mesh (II) is almost 
completely formed and other papillae have begun to form on the anther surface. The papillae on the anther surface take on a distinctive 'glove-like' multilobed (III) appearance during stage 4.

Figure 5: Semi quantitative RT PCR analysis of expression of all Solanum lycopersicum R2R3 MYB subgroup 9 genes during development of the flower.

Stages 1 to 4 are the first 4 developmental stages shown in Figure 4. Flower developmental stages are labelled above each lane, and the number of cycles is indicated. Positive and negative controls were conducted for each primer set (not shown): the positive control was the same primers amplifying from a plasmid containing the sequenced gene, the negative control was the same primers with only water. SlCAC was used as a reference gene (lower panels) 


\begin{tabular}{|l|l|}
\hline Gene & eFP browser prediction \\
\hline SIMIXTA-1 & Unopened flower buds \\
\hline SIMIXTA-2 & Leaves \\
\hline SIMIXTA-3 & Unopened flower buds \\
\hline SIMIXTA-4 & Unopened flower buds and mature flowers \\
\hline SIMIXTA-like-1 & Unopened flower buds, leaves and fruit \\
\hline SIMYB17-1 & Low levels in green fruit \\
\hline SIMYB17-2 & $\begin{array}{l}\text { Unopened flower buds, mature flowers. } \\
\text { Lower expression throughout leaves. }\end{array}$ \\
\hline
\end{tabular}

Table 1: A table summarising the expression of the R2R3 MYB subgroup 9 candidate genes in Solanum lycopersicum.

This table summarises expression levels predicted by the eFP browser for the candidate genes. 


\section{Figure 1}

$1 \mathrm{~A}$

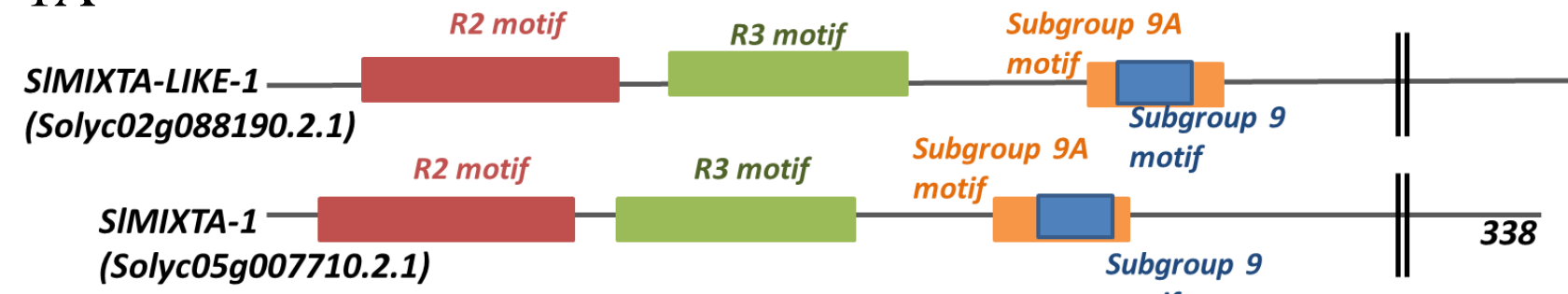

(Solyc05g007710.2.1)

R2 motif

R3 motif

ubgroup 9

Subgroup 9A motif

SIMIXTA-2

(Solyc04g005600.1.1)
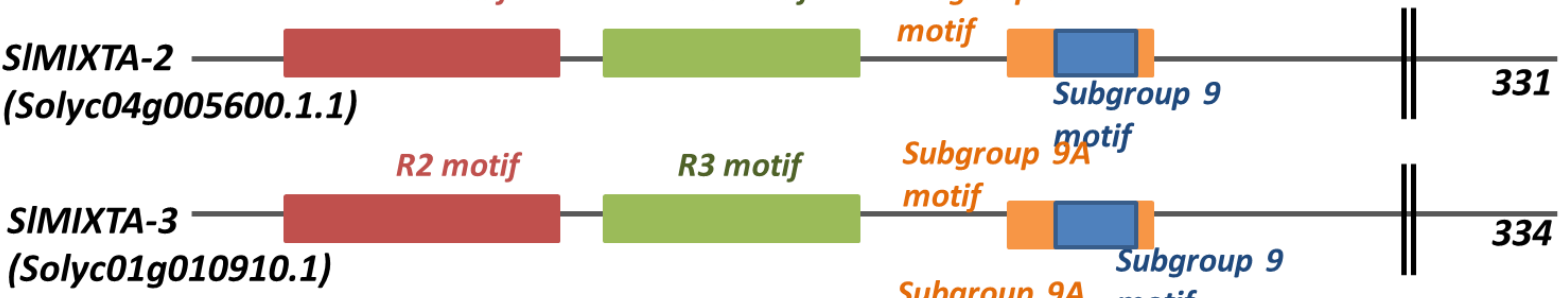

(Solyc01g010910.1)

SIMIXTA-4

R2 motif

R3 motif

(Solyc05g007690.1)

Subgroup 9A motif

-

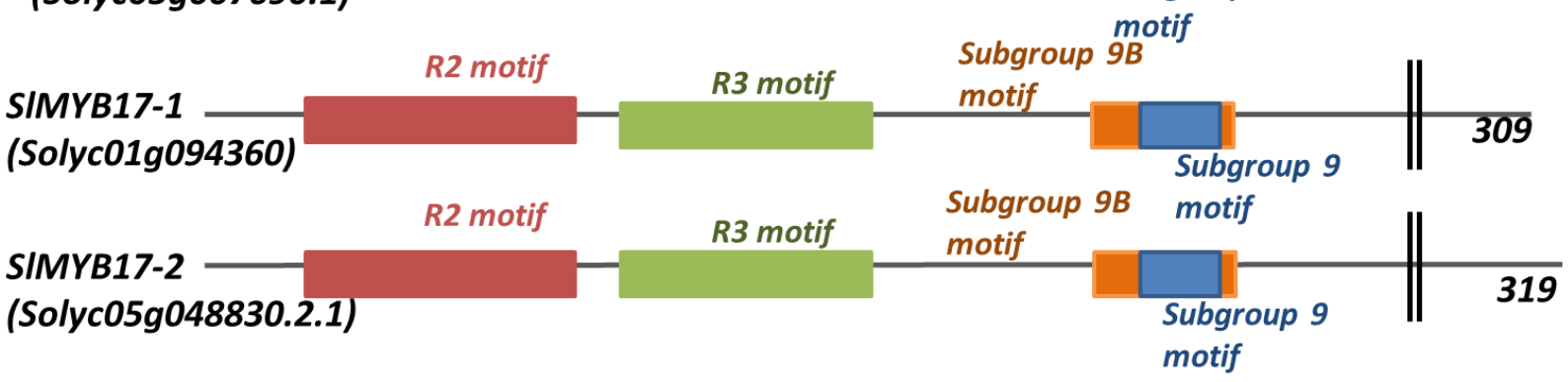

1B

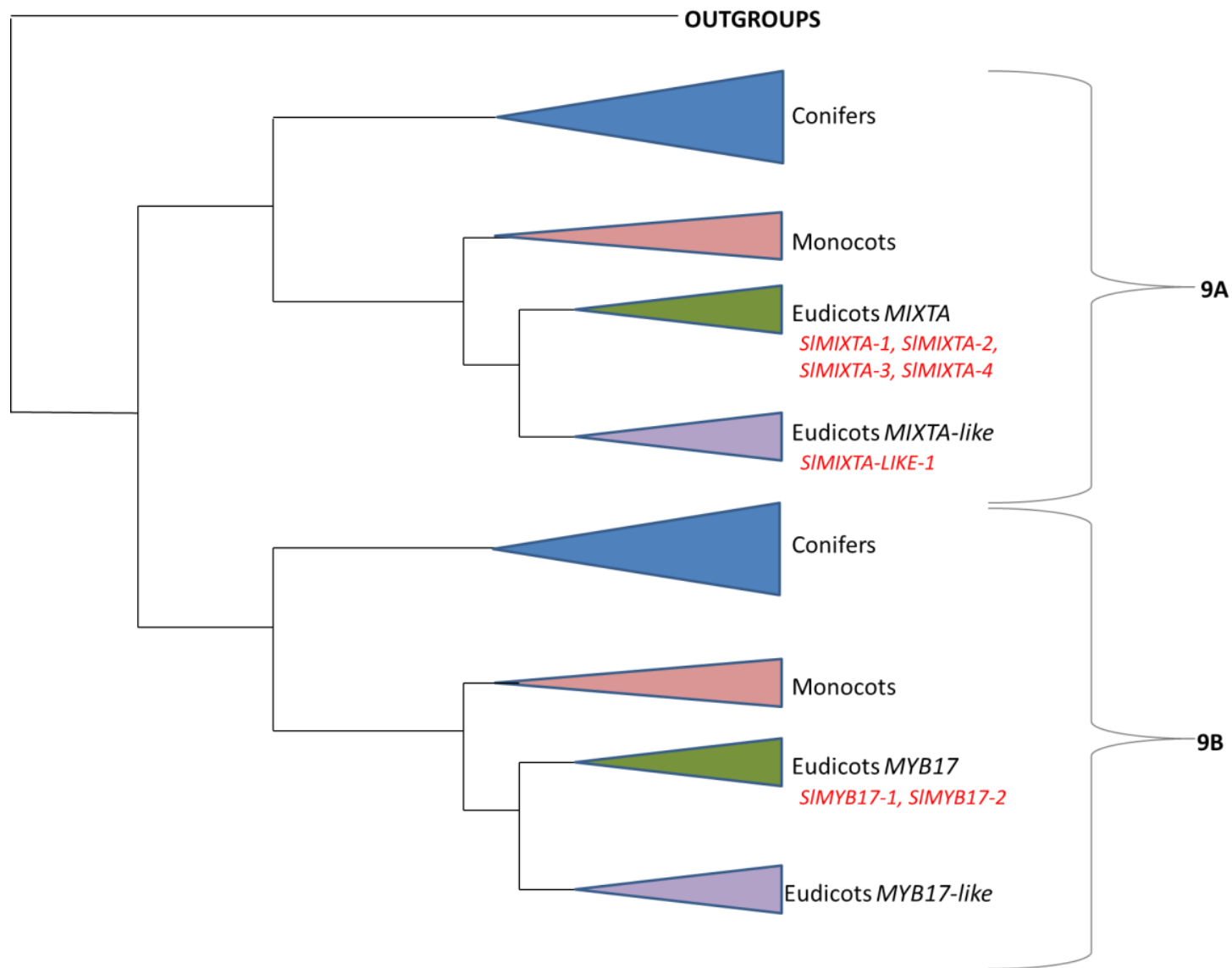


Figure 1A: Cartoon of the proteins of the R2R3 MYB subgroup 9 genes of Solanum lycopersicum, with key motifs labelled.

Sol genomics codes are displayed beneath name the transcription factor is referred to within this paper. Lengths displayed are total amino acids.

Figure 1B: Cartoon phylogeny of the R2R3 MYB Subgroup 9 family of transcription factors. Based on reconstruction by Brockington et al 2013. Placement of R2R3 subgroup 9 transcription factors within tomato is indicated. 
Figure 2

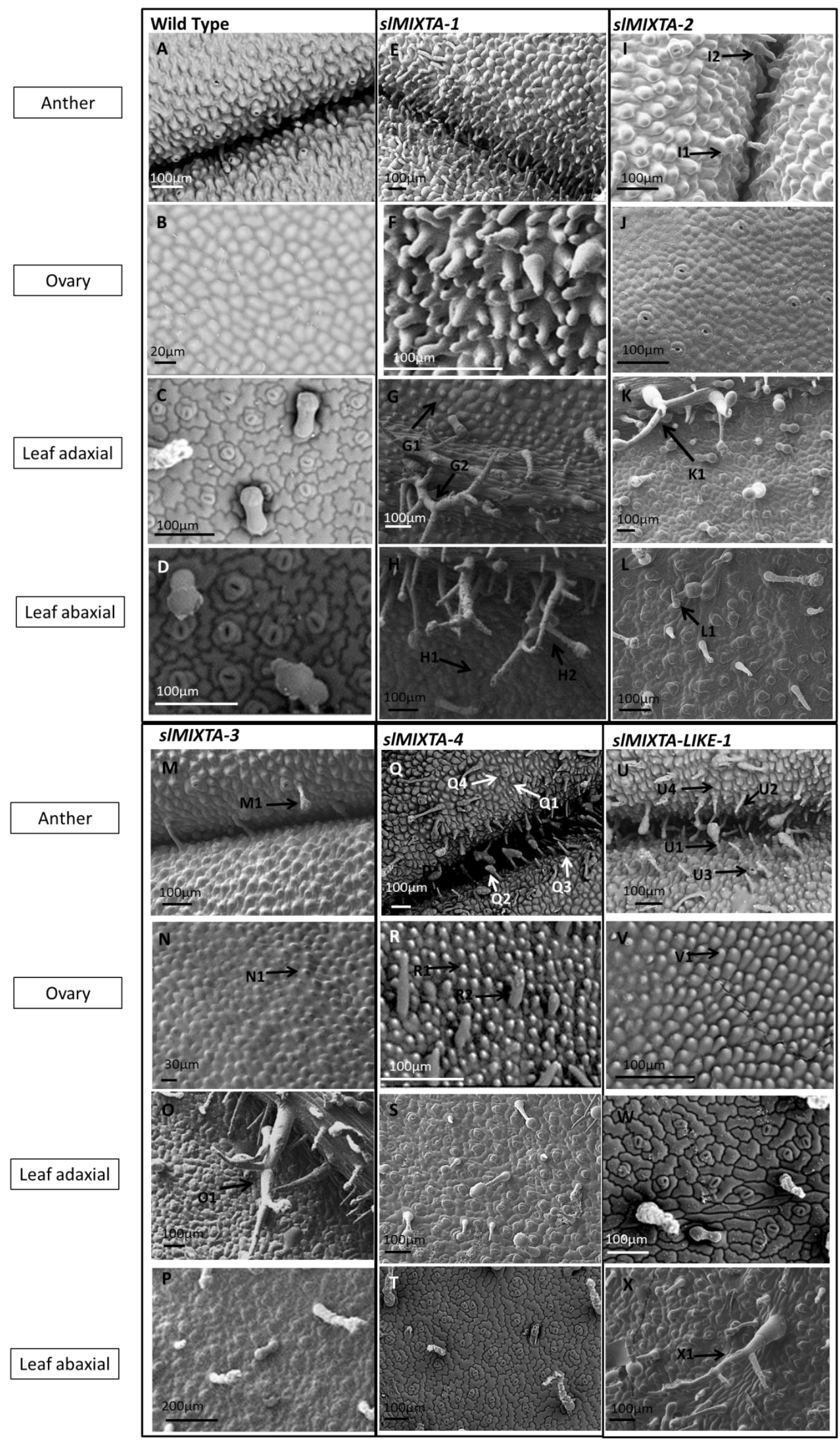


Figure 2: SEM images of key tissues of transgenic tobacco ectopically expressing the Solanum lycopersicum subgroup 9A genes.

The images shown are representative individuals of each line, from which a minimum of 5 individuals were examined per line. Wild-type tobacco tissues are shown as comparison. The tissues shown are anther surface and ovary surface as these tissues showed the most distinctive transgenic phenotypes and showed the most variation with expression of the different genes. A: WT tobacco anther, B: WT ovary epidermal surface. C: WT adaxial leaf surface. D: WT abaxial leaf surface. E: Anther surface of tobacco ectopically expressing SIMIXTA-1. F: Ovary surface of tobacco ectopically expressing SIMIXTA-1. G: Adaxial leaf surface of tobacco ectopically expressing SIMIXTA-1, G1 labels ectopic conical cells, G2 labels ectopic branched trichome. H: Abaxial leaf surface of tobacco ectopically expressing SIMIXTA-1, H1 labels ectopic conical cells, $\mathrm{H} 2$ labels ectopic branched trichome. I: Anther surface of tobacco ectopically expressing SIMIXTA-2, I1 labels ectopic glandular trichome, I2 labels ectopic non-glandular trichome. J: Ovary surface of tobacco ectopically expressing SIMIXTA-2. K: Adaxial leaf surface of tobacco ectopically expressing SIMIXTA-2, K1 labels ectopic branched trichome. L: Abaxial leaf surface of tobacco ectopically expressing SIMIXTA-2, L1 labels ectopic branched trichome. M: Anther surface of tobacco ectopically expressing SIMIXTA-3, M1 labels ectopic glandular trichome. N: Ovary surface of tobacco ectopically expressing SIMIXTA-3, N1 labels ectopic conical cells. O: Adaxial leaf surface of tobacco ectopically expressing SIMIXTA-3, O1 labels ectopic branched trichome. P: Abaxial leaf surface of tobacco ectopically expressing SIMIXTA-3. Q: Anther surface of tobacco ectopically expressing SIMIXTA-4, Q1 labels ectopic conical cells, Q2 labels ectopic guard cells, Q3 labels ectopic non-glandular trichome, Q4 labels ectopic glandular trichome. R: Ovary surface of tobacco ectopically expressing SIMIXTA-4, R1 labels ectopic conical cells, R2 labels ectopic non-glandular trichome. S: Adaxial leaf surface of tobacco ectopically expressing SIMIXTA-4. T: Abaxial leaf surface of tobacco ectopically expressing SIMIXTA-4. U Anther surface of tobacco ectopically expressing SIMIXTA-like-1, U1 labels ectopic glandular trichome, U2 labels ectopic non-glandular trichome, U3 labels ectopic guard cell, U4 labels ectopic conical cell. V: Ovary surface of tobacco ectopically expressing SIMIXTA-like-1, V1 labels ectopic conical cell. W: Adaxial leaf surface of tobacco ectopically expressing SIMIXTA-like-1. X:Abaxial leaf surface of tobacco ectopically expressing SIMIXTA-like-1, X1 labels ectopic branched trichome. 
Figure 3

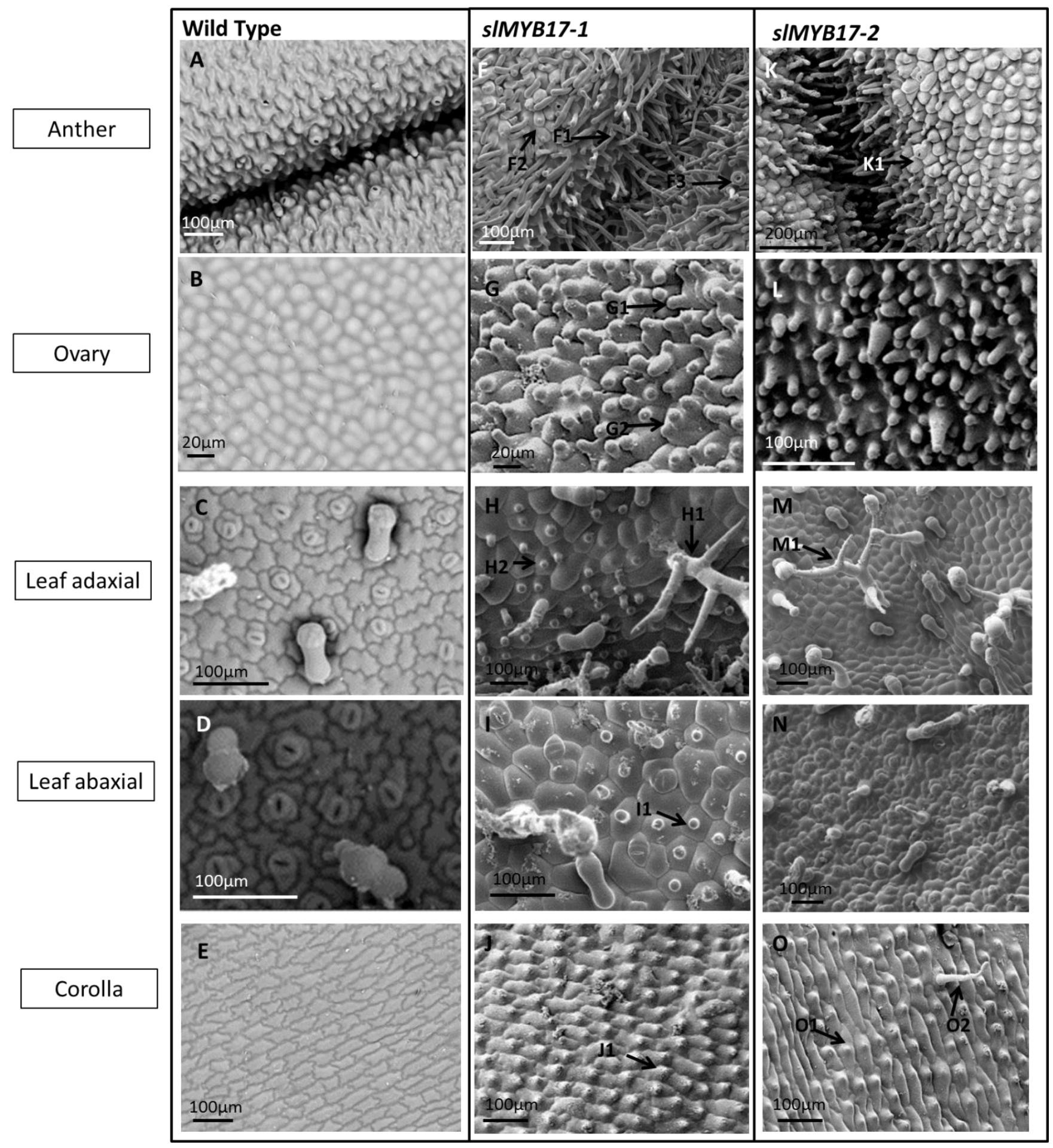


Figure 3: The transgenic phenotypes of lines of tobacco ectopically expressing each of the R2R3 MYB subgroup 9B genes of tomato.

The images shown are representative individuals of each line, from which a minimum of 5 individuals were examined per line. Wild-type tobacco tissues are shown as comparison. The tissues shown are anther surface and ovary surface as these tissues showed the most distinctive transgenic phenotypes and showed the most variation with expression of the different genes. A: WT tobacco anther. B: WT ovary epidermal surface. C: WT adaxial leaf surface. D: WT abaxial leaf surface. E: WT corolla surface. F: Anther surface of tobacco ectopically expressing SIMYB17-1, F1 labels ectopic trichomes, F2 labels ectopic conical cells. G: Ovary surface of tobacco ectopically expressing SIMYB17-1, G1 labels ectopic trichome like outgrowths, G2 labels multilobed outgrowths. H: Adaxial leaf surface of tobacco ectopically expressing SIMYB17-1, H1 labels ectopic branched trichome, H2 labels ectopic conical cells. I: Abaxial leaf surface of tobacco ectopically expressing SIMYB17-1, I1 labels ectopic conical cells. J: Corolla surface of tobacco expressing SIMYB17-1, J1 labels ectopic conical cells. K: Anther surface of tobacco ectopically expressing SIMYB17-2, K1 labels ectopic guard cells on top of cell outgrowths. L: Ovary surface of tobacco ectopically expressing SIMYB17-2. M: Adaxial leaf surface of tobacco expressing SIMYB17-2, M1 labels ectopic branched trichome. N: Abaxial leaf surface of tobacco expressing SIMYB17-2. O: Corolla surface of tobacco expressing SIMYB17-2, O1 labels ectopic conical cells, O2 labels ectopic trichome. 
Figure 4

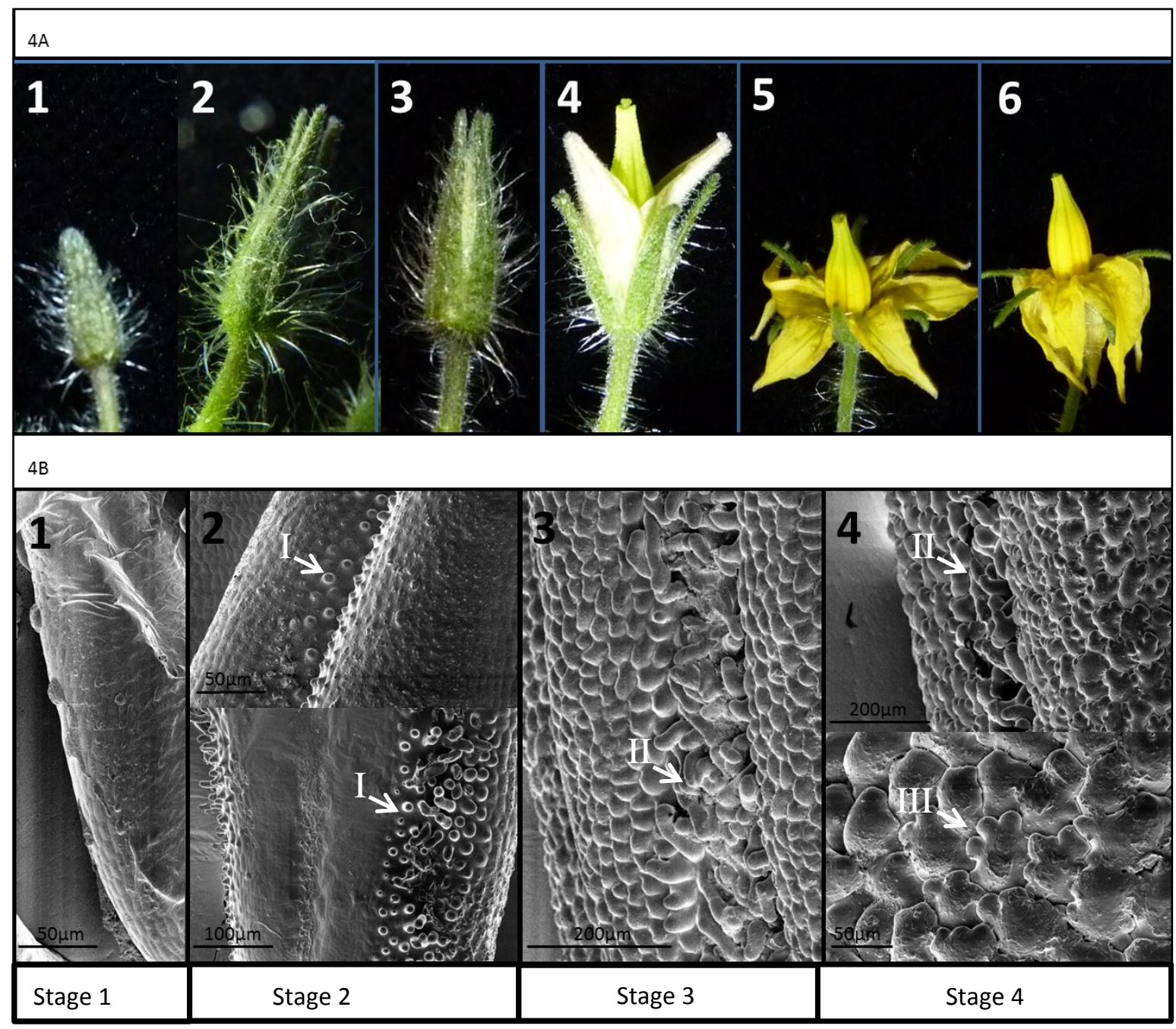

Figure 4: The stages of floral development and the anther epidermal cell outgrowths of Solanum lycopersicum.

A. Six stages of tomato flower development chosen to reflect the development of the epidermal cell outgrowths on tomato anthers. B. SEM images of anther surface at stages 1 to 4 . Epidermal cell outgrowths begin to develop at stage 2 (I). By stage 3 the anther trichome mesh (II) is almost completely formed and other papillae have begun to form on the anther surface. The papillae on the anther surface take on a distinctive 'glove-like' multilobed (III) appearance during stage 4. 

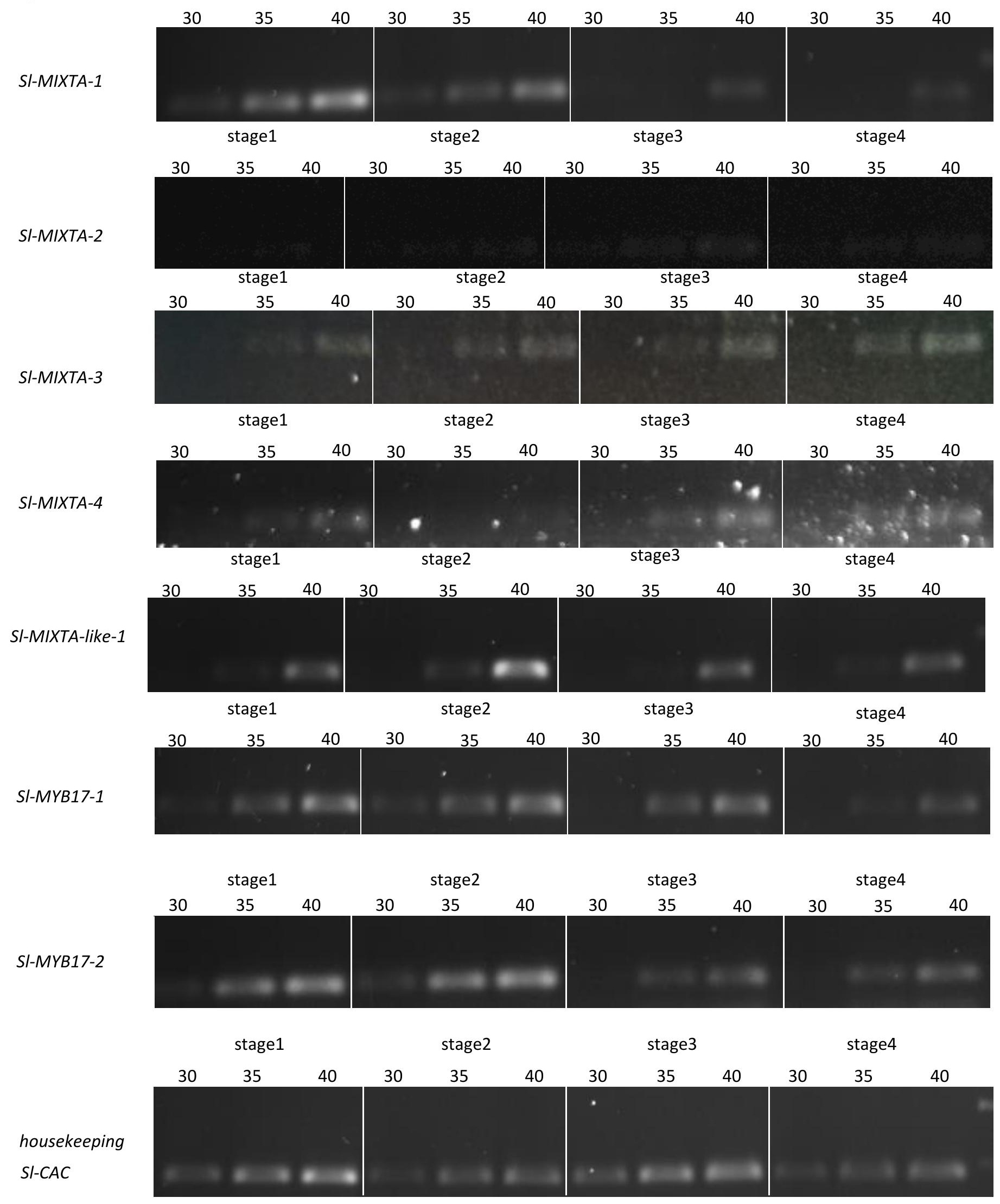
Figure 5: Semi quantitative RT PCR analysis of expression of all Solanum lycopersicum R2R3 MYB subgroup 9 genes during development of the flower.

Stages 1 to 4 are the first 4 developmental stages shown in Figure 4. Flower developmental stages are labelled above each lane, and the number of cycles is indicated. Positive and negative controls were conducted for each primer set (not shown): the positive control was the same primers amplifying from a plasmid containing the sequenced gene, the negative control was the same primers with only water. SICAC was used as a reference gene (lower panels). 